\title{
Avaliação da qualidade hídrica de poços de abastecimento do município de Juína, MT-Brasil
}

A água é um elemento fundamental para todos os seres vivos, atuando diretamente na manutenção dos ecossistemas e ao equilíbrio ambiental e ecológico. Em Juína, é comumente utilizada água provenientes de poços, porém, estes são frequentemente construídos sem critérios técnicos adequados, tornando está água mais susceptível à contaminação. Dessa forma, o presente trabalho buscou avaliar a qualidade da água de poços de abastecimento do bairro Módulo VI, confrontando os resultados com os padrões de potabilidades estabelecidos pela Portaria no 05/2017 do Ministério da Saúde. Para a coleta das amostras foi utilizada a metodologia proposta no Standard Methods for the Examination of Water and em duas campanhas. A primeira campanha foi realizada no mês de março de 2019, período de elevado índice pluviométrico, e a segunda campanha foi realizada no mês de julho de 2019 , mês este de escassez hídrica do município. Foram analisadas amostras de água de dez poços de abastecimento, distribuídos de forma aleatória no bairro. Os parâmetros analisados foram alcalinidade, cloretos, dureza cálcio, pH, condutividade elétrica, ferro, coliformes totais e termotolerantes. Para as análises físico-químicas, utilizou-se de medidores digitais e titulometria, respectivamente, e para as análises microbiológicas avaliou-se o desenvolvimento de colônias de bactérias em cartelas de substrato cromogênico (Colipaper). Com o intuito de verificar os efeitos da sazonalidade sobre os elementos analisados, adotou-se o delineamento experimental inteiramente casualizado, com dois tratamentos (seco e chuvoso) e os dados dos parâmetros físico-químicos foram comparados por meio de análise de variância, em nível de 5\% de probabilidade pelo teste de Fischer (Teste F). As diferenças encontradas foram comparadas por meio do teste de Scott-Knott em nível de $5 \%$ de probabilidade e submetidos ao teste de correlação de Pearson também em nível de $5 \%$ de probabilidade. Deste modo, conclui-se que a população do bairro Módulo VI, está consumindo água fora dos padrões de potabilidade estabelecido pela legislação brasileira, podendo refletir diretamente na saúde da população consumidora. Os resultados expostos nesse trabalho evidenciam a necessidade da implantação de medidas mitigadoras de forma efetiva bem como, a necessidade de monitoramento contínuo da qualidade da água do bairro Módulo Vl.

Palavras-chave: Potabilidade; Águas subterrâneas; Sazonalidade.

\section{Evaluation of the water quality of supply wells in the municipality of Juína, MT-Brazil} \begin{abstract}
Water is a fundamental element for all living beings, acting directly in the maintenance of ecosystems and the environmental and ecological balance. In Juina, water from wells is commonly
used, however, these are often built without adequate technical criteria, making this water more susceptible to contamination. Thus, the present study sought to assess the water quality of used, however, these are often built without adequate technical criteria, making this water more susceptible to contamination. Thus, the present study sought to assess the water quality of
supply wells in the Module VI neighborhood, comparing the results with the portability standards established by Ordinance No. $05 / 2017$ of the Ministry of Health. For the collection of supply wells in the Module VI neighborhood, comparing the results with the portability standards established by Ordinance No. 05/2017 of the Ministry of Health. For the collection of
samples, the methodology was used proposed in the Standard Methods for the Examination of Water and in two campaigns. The first campaign was carried out in March 2019, a period of high rainfall, and the second campaign was carried out in July 2019, this month of water scarcity in the municipality. Water samples from ten supply wells were randomly distributed in the neighborhood. The parameters analyzed were alkalinity, chlorides, hardness, calcium, $\mathrm{pH}$, electrical conductivity, iron, total and thermotolerant coliforms. For physical-chemical analyzes, digital meters and titrometry were used, respectively, and for microbiological analyzes, the development of bacterial colonies on chromogenic substrate cards (Colipaper) was evaluated. In order to verify the effects of seasonality on the analyzed elements, a completely randomized experimental design was adopted, with two treatments (dry and rainy) and the data of the physical-cos physical test at a levelof

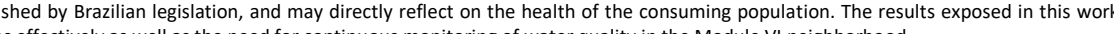
demonstrate the need to implement mitigation measures effectively as well as the need for continuous monitoring of water quality in the Module VI neighborhood.
\end{abstract}

Keywords: Potability; Groundwater; Seasonality

Topic: Engenharia Ambiental

Reviewed anonymously in the process of blind peer.
Received: 02/02/2021

Approved: 25/02/2021
Vanessa Caroline Manochio (iD)

Instituto Federal de Mato Grosso, Brasil http://lattes.cnpq.br/0318960525557853 http://orcid.org/0000-0002-0250-0004 vanessa.manochio@gmail.com

Alan Cândido da Silva (iD)

Instituto Federal de Rondônia, Brasil http://lattes.cnpq.br/4073411142396847 http://orcid.org/0000-0002-7515-3330

alan.silva@ifro.edu.br

Josiane de Brito Gomes (iD)

Instituto Federal de Mato Grosso, Brasil http://lattes.cnpq.br/5211517848918453 http://orcid.org/0000-0001-5870-6776 josiane.brito@jna.ifmt.edu.br

DOI: 10.6008/CBPC2179-6858.2021.002.0031

\section{Referencing this:}

MANOCHIO, V. C.; SILVA, A. C.; GOMES, J. B.. Avaliação da qualidade hídrica de poços de abastecimento do município de Juína, MT-Brasil. Revista Ibero Americana de Ciências Ambientais, v.12, n.2, p.343358, 2021. DOI: http://doi.org/10.6008/CBPC21796858.2021.002.0031 


\section{INTRODUÇÃO}

Por suas múltiplas utilizações, a água, solvente universal é indispensável para todos os seres vivos, atuando diretamente na manutenção dos ecossistemas e ao equilíbrio ambiental e ecológico. Encontrar este recurso em seus níveis ideais de potabilidade, tem sido um desafio, visto que os efeitos da urbanização, atividades agrícolas e industriais são cada vez mais pronunciadas, o que afeta diretamente a disponibilidade e a qualidade hídrica. Embora a água seja um dos constituintes inorgânicos mais abundante do planeta terra, está, não apresenta uma distribuição uniforme e nem sempre, atende aos padrões de potabilidade exigidos pelas legislações vigentes. Estima-se que $11 \%$ da população mundial não dispõe de água doce de qualidade em sua residência e em consequência, cerca de 526 mil crianças morrem anualmente (WHO et al., 2017).

As principais utilizações da água no Brasil são para a irrigação, indústria, geração de energia, mineração, aquicultura, navegação, turismo e lazer e sobretudo para o abastecimento humano (ANA, 2017). Uma alternativa para o abastecimento humano são os mananciais subterrâneos. Segundo Souza (2015) “Á água subterrânea é toda aquela que está abaixo da superfície da terra, preenchendo os espaços vazios intergranulares do solo, das rochas sedimentares ou fraturas, falhas e fissuras das rochas compactas".

Até meados da década de 70, acreditava-se que as águas subterrâneas eram isentas ou menos susceptíveis às contaminações, devido a proteção das camadas de rochas e de solos, porém, hoje sabe-se, que os efeitos da urbanização e das ações antrópicas podem impactar diretamente na qualidade da água dos mananciais subterrâneos (GROTT et al., 2017). Em áreas expostas ao crescimento populacional as águas subterrâneas podem sofrer transformações nas suas propriedades físico-químicas e microbiológicas em decorrência do aporte de substâncias provenientes da atuação humana, que resulta na contaminação dessas águas. Dentre os principais contaminantes da água subterrânea, destacam-se o lixiviado dos aterros sanitários e a modernização da agricultura (GOMES et al., 2018; BRAGAGNOLO et al., 2018).

Segundo a Portaria no 05/2017 do Ministério da Saúde (MS), a água destinada ao consumo humano deve ser consumida de forma racional, devendo a mesma ser potável, ou seja, deve ser tratada, limpa e estar livre de qualquer contaminação, seja está de origem microbiológica, química, física ou radioativa, para que não ofereça riscos à saúde humana (BRASIL, 2017). As águas destinadas ao consumo humano que não atendem aos padrões de potabilidade estabelecidos pela Portaria MS no 05/2017, podem ser fontes de transmissão de doenças de veiculação hídrica, como a hepatite, malária, febre amarela, cólera, esquistossomose, dengue, hantavirose e a leishmaniose (SOUZA, 2015).

No Brasil, as doenças de veiculação hídrica que mais resultam em internações hospitalares são a amebíase, a cólera, febres tifoides e paratifoides, shiguelose, diarreia e gastroenterite de origem infecciosa (ANA, 2017). Neste sentido, a Organização Mundial da Saúde (OMS), salienta que cerca de $3,1 \%$ dos óbitos no mundo, compreendendo cerca de 1,7 milhões de pessoas, são devido a qualidade imprópria da água (ANA, 2013), e no Brasil, de acordo com os registros do Sistema Único de Saúde (SUS), cerca de 80\% das internações Hospitalares são resultados de doenças de veiculações hídricas (MERTEN et al., 2002).

Desde a fundação do bairro Módulo VI, em Juína, este perpassa por situações infraestruturais 
complexas. O bairro foi fundado inicialmente, para abrigar famílias em vulnerabilidade socioeconômica e por conta do desenvolvimento acelerado do bairro Módulo V, limítrofe ao bairro em estudo. Anteriormente, a área era ocupada para disposição de resíduos sólidos a céu aberto. Com a crescente expansão deste bairro, os problemas relacionados ao saneamento básico são ocorrentes no local, sendo comum ruas sem pavimentação, lotes em condições irregulares e ausência de rede de esgoto.

Quanto à fonte de suprimento de água, cerca de 701 residências desfrutam de serviço de água tratada, o restante dispõe de poços rasos em suas propriedades (ARAÚJO, 2014). Porém, estes são preponderantemente construídos sem critérios técnicos adequados, tornando está água mais susceptível à contaminação e expondo a saúde da população consumidora. Diante de eminentes riscos sanitários, a avaliação das condições sanitárias da água subterrânea, sobretudo em relação aos parâmetros químicos, físicos e microbiológicos são de grande relevância para prevenir possíveis patologias de veiculação hídrica e fornecer subsídios para a implantação de medidas mitigadoras que reflitam em uma melhor qualidade de vida para a população.

Nesse sentido, objetivou-se com o presente trabalho analisar a qualidade das águas subterrâneas do bairro Módulo VI no município de Juína - MT usada pela população, comparando com os padrões de potabilidade apresentados na Portaria № 05/2017 do Ministério da Saúde.

\section{MATERIAIS E MÉTODOS}

\section{Caracterização da área de estudo}

A pesquisa foi conduzida no bairro Módulo VI, localizado no município de Juína, a noroeste do estado de Mato Grosso. Situada à 730 quilômetros da capital Cuiabá. Juína localiza-se à uma altitude de 442 metros em relação ao nível do mar, nas coordenadas geográficas de latitude $11022^{\prime} 42^{\prime \prime}$ sul e a uma longitude 58으 44' 28" (Figura 1). Com uma extensão territorial de 26.189,919 $\mathrm{Km}^{2}$, o município de Juína conta com uma população de 39.255 habitantes (IBGE, 2010).

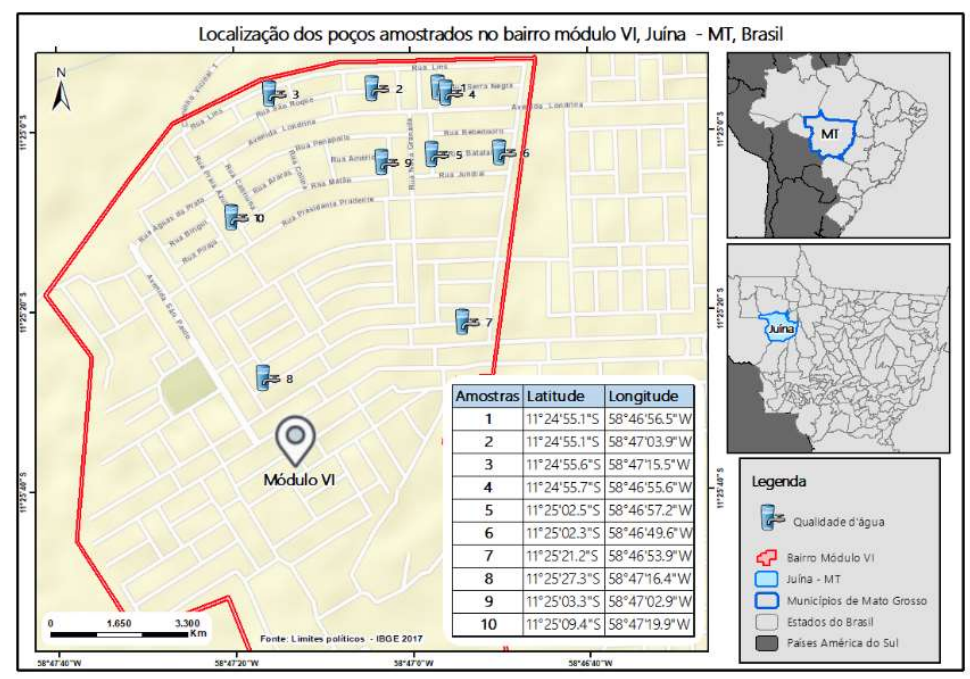

Figura 1: Localização do Município de Juína, com destaque da área de estudo demostrando os 10 pontos amostrais.

A precipitação média anual é de $2250 \mathrm{~mm}$, com estação seca e chuvosa bem definida, sendo o clima 
classificado como AW, segundo Köppen (1948), com temperatura média anual de $24^{\circ} \mathrm{C}$. A região onde o município de Juína está inserido apresenta formações florestais classificadas como floresta ombrófila aberta e floresta estacional, situando-se no ecótono Amazônia-cerrado. A hidrografia da região compreende a bacia Amazônica, tendo como principal manancial de abastecimento o rio Perdido. Os solos predominantes na região são do tipo Latossolo vermelho escuro, sendo solos profundos com texturas argilúvicas (FRANÇA, 2016).

\section{Coleta das amostras}

As amostras foram coletadas em dez pontos amostrais distribuídos equitativamente nas diferentes localidades. Foram selecionados aleatoriamente três poços com cotas altimétricas altas, quatro com cotas altimétricas baixas e três situados no fragmento central a fim de se conhecer a qualidade físico-química e microbiológica da água em toda a região do bairro (Figura 2). Dessa forma, analisou-se empiricamente as condições higiênico-sanitárias dos poços, como: profundidade, distância aproximada do poço e fossa, vedação e localidades próximas a lançamentos de esgotos in natura. As coletas ocorreram no mês de março e julho de 2019 no período matutino, seguindo os métodos propostos pela Standard Methods for the Examination of Water and Wastewater (APHA, 1995).

Previamente à coleta da água, a assepsia das torneiras foram realizadas com álcool $70 \%$ e flambadas em seguida por três vezes. Posteriormente, deixou-se a água fluir de 2 a 3 minutos antes da coleta (FUNASA, 2006). Para a coleta, utilizou-se frascos de polietileno de $500 \mathrm{~mL}$, esterilizados em autoclave (Modelo AV 75) à temperatura de $121^{\circ} \mathrm{C}$ por 20 minutos. As amostras foram identificadas por data, hora e pontos de coleta, acondicionadas em caixa isotérmicas com gelo e conduzidas até o laboratório de Química do IFMT campus Juína onde realizou-se as análises.

\section{Análise dos parâmetros}

Os parâmetros físico-químicos analisados, foram: alcalinidade, cloretos, dureza, cálcio, magnésio, pH, condutividade elétrica, ferro e os microbiológicos foram coliformes totais e termotolerantes. Para as análises de $\mathrm{pH}$ e condutividade elétrica, utilizou-se Medidor de $\mathrm{pH}$ de Bancada Microprocessador e condutivímetro, respectivamente.

As análises de alcalinidade, dureza, cálcio, magnésio, foram realizadas pelo método titulométrico, que segundo Silva et al. (2014) "busca determinar a quantidade de uma substância em solução, medindo-se a quantidade necessária de um reagente para reagir completamente com toda essa substância". Para a realização das análises do parâmetro ferro e cloretos foi utilizado o kit básico de potabilidade da água (Alfakit ${ }^{\circledR}$ ), devido sua praticidade e confiabilidade, como citado por Zan et al. (2012) e Bortoli (2016).

Para as análises microbiológicas avaliou-se o desenvolvimento de colônias de bactérias em cartelas de substrato cromogênico (Colipaper), neste método é possível observar a presença de coliformes totais e termotolerantes (Escherichia coli), em uma mesma cartela, pois o mesmo faz a combinação de dois substratos cromogênicos. Para as análises microbiológicas, seguiu as seguintes etapas orientadas pela 
Alfakit ${ }^{\circledR}$. A Tabela 1 sintetiza os parâmetros e as respectivas metodologias de análise.

Tabela 1: Metodologias empregadas nas análises físico-químicas e microbiológicas para a análise da qualidade da água dos poços do bairro Módulo VI.

\begin{tabular}{|c|c|c|}
\hline Parâmetros & Métodos & Marca/Modelo \\
\hline Alcalinidade $\left(\mathrm{mg} \mathrm{CaCO}_{3} \cdot \mathrm{L}^{-1}\right)$ & Titulação com ácido sulfúrico 0,01M & - \\
\hline Cloretos (mg. $\left.\mathrm{L}^{-1}\right)$ & Titulação Precipitação-Argentimétrico & Alfakit $^{\circledast}$ \\
\hline Dureza $\left(\mathrm{mg} \mathrm{CaCO}_{3} \cdot \mathrm{L}^{-1}\right)$ & Titulação com EDTA 0,01 mol L-1 & - \\
\hline Cálcio (mg. $\left.\mathrm{L}^{-1}\right)$ & Titulação com EDTA & - \\
\hline Magnésio (mg. $\mathrm{L}^{-1}$ ) & Titulação com EDTA & - \\
\hline $\mathrm{pH}$ & Medidor de pH de Bancada & PHOX P1000 \\
\hline Condutividade elétrica $(\mu \mathrm{s} / \mathrm{cm})$ & Condutívimetro & MS TECNOPON mPA-210p \\
\hline Ferro (mg. $\left.\mathrm{L}^{-1}\right)$ & Titulação com ácido tioglicólico & Alfakit $^{\circledR}$ \\
\hline Coliformes Totais (UFC/mL) & Colipaper & Alfakit $^{\circledast}$ \\
\hline Coliformes Termotolerantes (UFC/mL) & Colipaper & Alfakit $^{\circledast}$ \\
\hline
\end{tabular}

\section{Análises estatísticas dos dados}

Todas as análises foram realizadas em triplicata e foram calculados os valores médios dos resultados, com a finalidade de se obter uma maior confiabilidade dos resultados.

Os dados dos parâmetros físico-químicos nos diferentes pontos amostrados foram comparados quantitativamente, por meio de análise de variância, em nível de 5\% de probabilidade pelo teste de Fischer (Teste F), para identificar as variações ocorridas nas duas épocas do ano (períodos de seca e chuvoso). Dessa forma, adotou-se o delineamento experimental inteiramente casualizado, com dois tratamentos (seco e chuvoso).

As diferenças encontradas foram comparadas por meio de teste de Scott-Knott, também em nível de 5\% de probabilidade, utilizando-se o software SISVAR, versão 5.4 (FERREIRA, 2008). Foram assumidos os pressupostos de normalidade e homocedasticidade. As correlações entre os parâmetros físico-químicos da água dos poços analisados foram testadas através de correlação de Person também em nível de $5 \%$ de probabilidade.

Os resultados das análises foram comparados com os valores máximos permitidos (VMP) apresentados pela Portaria no 05/2017 do Ministério da Saúde, permitindo inferir sobre a potabilidade da água. Adicionalmente, o manancial foi classificado de acordo com os pressupostos da Resolução CONAMA no $396 / 2008$.

\section{RESULTADOS E DISCUSSÃO}

\section{Avaliação das condições higiênico-sanitárias}

Avaliar as condições higiênico-sanitárias dos poços e a sua localização, é um importante fator no que tange à saúde da população consumidora, sobretudo, nas crianças e idosos que constituem uma faixa etária mais susceptível as doenças de veiculações hídricas (CAPP et al., 2012).

Foi observado in situ que os poços de abastecimentos analisados do bairro Módulo VI, são construídos em sua maioria, sem critérios técnicos adequados, estando em desconformidade ao exposto pela Norma Brasileira (NBR) da Associação Brasileira de Normas Técnicas (ABNT) no 12.244/1992, que fixa as 
condições necessárias para a captação da água subterrânea com a finalidade do abastecimento público. Tal condição pode comprometer a qualidade da água captada e, consequentemente, expor a saúde da população que utiliza esse recurso. Cabe destacar que no bairro, por questões culturais e econômicas é frequente a perfuração de poços pelos próprios moradores, mesmo em locais onde a população desfruta da oferta de água tratada. Situação semelhante a esta também foi encontrada por Raposa et al. (2017) ao analisarem a qualidade da água de poços de abastecimento no bairro São José Operário em Juína - MT.

Dos poços analisados, todos encontraram-se em desconformidade com a legislação, possuindo vedação precária ou inapropriada e sem calçada ao redor, o que pode facilitar a entrada de vetores, como baratas e outros insetos. No poço 7 (Figura 2) é possível observar a vedação inadequada, que pode expor a qualidade da água subterrânea, visto que a percolação da água da chuva, pode trazer os contaminantes presentes na superfície para dentro do poço, pelas fissuras presentes na tampa. Capp et al. (2012), ao analisar a qualidade da água de 12 poços rasos em Anastácio - MS, verificou que as condições higiênico-sanitárias são responsáveis pela contaminação da água.

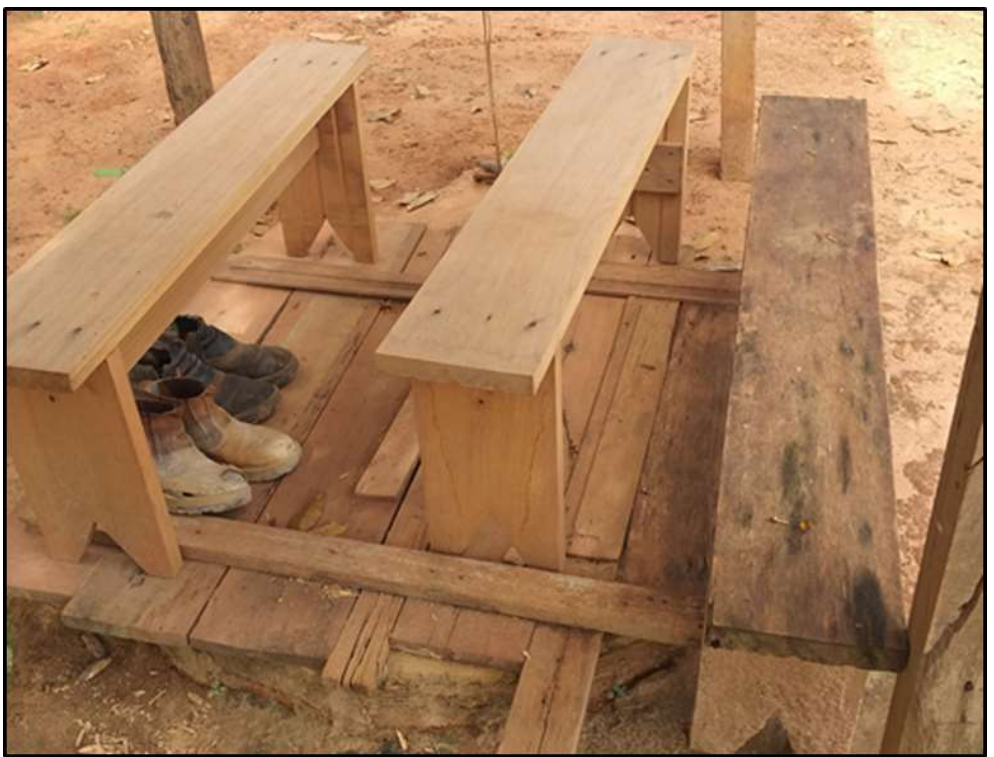

Figura 2: Condições precárias do Poço 7 do bairro Módulo VI, em Juína - MT.

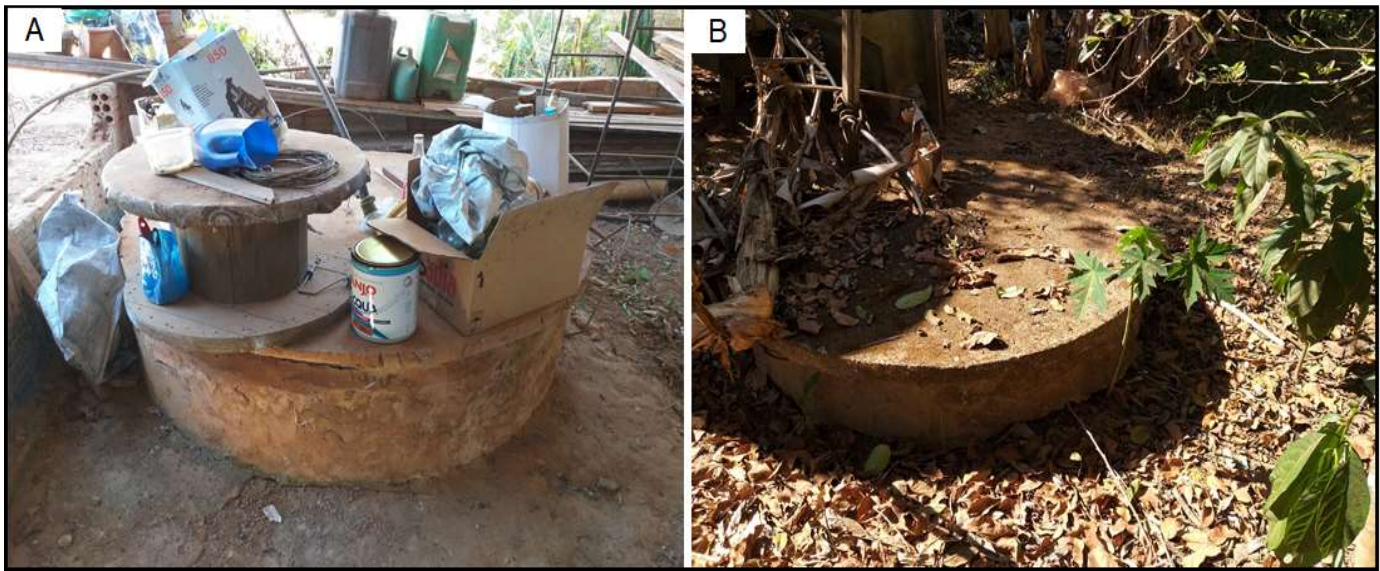

Figura 3: Condições de limpeza inadequada no entorno dos poços do bairro Módulo VI, em Juína - MT Legenda: (A) Ponto 1 (B) Ponto 3.

A falta de limpeza no entorno dos poços, como verificado no bairro Módulo VI (Figura 3), também é 
um fator preocupante que pode vir a comprometer a qualidade da água subterrânea, principalmente em poços rasos, dos quais podem estar mais sujeitos a influência da água decorrente do escoamento superficial, como observados nos poços amostrados (BASTOS, 2013).

A distância do poço em relação a fossa também é um fator significativo para preservar a qualidade da água, pois a localização inadequada, pode facilitar a ligação das fossas com as águas freáticas tornando a água propensa à contaminação ( $\mathrm{AYACH}, 2002)$.

Observou-se, que os poços mais distantes em relação às fossas são os P5 e P9 com 20 metros e o P1, P4 e P10 com 15 metros. Todavia o P7 situa-se a 3 metros da fossa e o P2 a 6 metros (Figura 4), estando em desacordo com a NBR no 7229/1992, que impõe uma distância mínima de 15 metros. Resultados semelhantes foram encontrados por Ayach (2002), em uma comunidade no estado do Mato Grosso do Sul, em que 16,7\% das fossas situavam-se a menos de $10,0 \mathrm{~m}$ de distância do poço e $41,7 \%$ na faixa de 10,0 a $20,0 \mathrm{~m}$.

Uma situação comumente observada no bairro Módulo VI, é a localização da fossa do terreno vizinho em relação à poços do entorno, para Ayach (2011), a declividade do terreno, pode consistir em um fator relevante de contaminação. A presença de fossas próximas dos poços, pode resultar em uma fonte de contaminação do lençol freático, principalmente por compostos nitrogenados, como nitrito, nitrato e amônia.

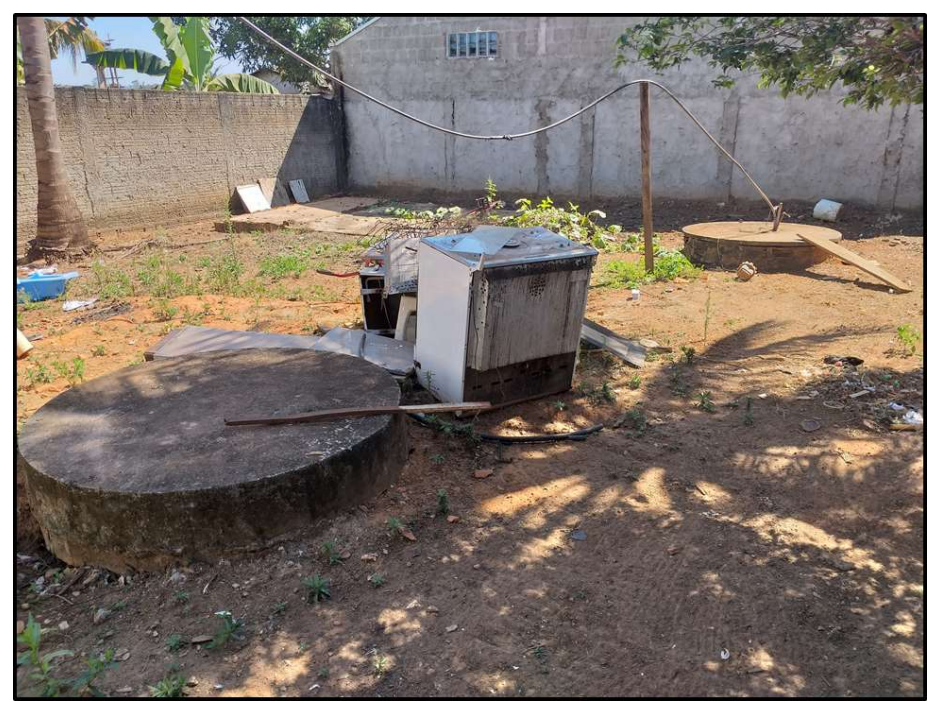

Figura 4: Localização do poço (P2) em relação a fossa, no bairro Módulo VI, em Juína - MT.

Dos dez poços analisados, $10 \%$ são do tipo raso com até 5 metros de profundidade, $70 \%$ entre 6 a 10 metros e $20 \%$ de 11 a 20 metros (Tabela 2). A profundidade dos poços é um dos fatores importantes de serem analisados, pois pode afetar diretamente a qualidade hídrica. Poços rasos como encontrados no estudo, estão mais propensos à contaminação por substâncias presentes na superfície do solo, principalmente por microrganismos patógenos.

Uma realidade semelhante foi constatada por Capp et al. (2012), que observaram que dos doze poços amostrados, 58,3\% possuía até 10 metros de profundidade, o que pode ser explicado pela característica delgada dos materiais inconsolidados da localidade, que propicia a perfuração de poços rasos e, por consequência, a contaminação das águas por fossas e disposição inadequada dos resíduos sólidos.

Brooks et al. (1979) ao analisarem a qualidade da água de poços rasos no leste rural do Texas, 
constataram que os poços com profundidade inferior a 15 metros apresentaram altas concentrações de coliformes fecais ou estreptococos fecais.

Tabela 2: Características estruturais dos dez (10) poços analisados no bairro Módulo VI, em Juína - MT.

\begin{tabular}{l|l|l|l|l}
\hline Poço & Profundidade $(\mathrm{m})$ & Distância Fossa-Poço $(\mathrm{m})$ & Vedação & Coordenadas geográficas \\
\hline P1 & 6 & 15 & Concreto & $11^{\circ} 24^{\prime} 55.1^{\prime \prime} \mathrm{S} 58^{\circ} 46^{\prime} 56.5^{\prime \prime} \mathrm{W}$ \\
\hline P2 & 7 & 6 & Concreto & $11^{\circ} 24^{\prime} 55.1^{\prime \prime} \mathrm{S} 58^{\circ} 47^{\prime} 03.9^{\prime \prime} \mathrm{W}$ \\
\hline P3 & 8 & 10 & Concreto & $1^{\circ} 24^{\prime} 55.6^{\prime \prime} \mathrm{S} 58^{\circ} 47^{\prime} 15.5^{\prime \prime} \mathrm{W}$ \\
\hline P4 & 8 & 15 & Concreto & $11^{\circ} 24^{\prime} 55.7^{\prime \prime} \mathrm{S} 58^{\circ} 46^{\prime} 55.6^{\prime \prime} \mathrm{W}$ \\
\hline P5 & 10 & 20 & Concreto & $11^{\circ} 25^{\prime} 02.5^{\prime \prime} \mathrm{S} 58^{\circ} 46^{\prime} 57.2^{\prime \prime} \mathrm{W}$ \\
\hline P6 & 6 & 10 & Concreto & $11^{\circ} 25^{\prime} 02.3^{\prime \prime} \mathrm{S} 58^{\circ} 46^{\prime} 49.6^{\prime \prime} \mathrm{W}$ \\
\hline P7 & 3 & 4 & Madeira & $11^{\circ} 25^{\prime} 21.2^{\prime \prime} \mathrm{S} 58^{\circ} 46^{\prime} 53.9^{\prime \prime} \mathrm{W}$ \\
\hline P8 & 18 & 10 & Concreto & $11^{\circ} 25^{\prime} 27.3^{\prime \prime} \mathrm{S} 58^{\circ} 47^{\prime} 16.4^{\prime \prime} \mathrm{W}$ \\
\hline P9 & 9 & 20 & Concreto & $11^{\circ} 25^{\prime} 03.3^{\prime \prime} \mathrm{S} 58^{\circ} 47^{\prime} 02.9^{\prime \prime} \mathrm{W}$ \\
\hline P10 & 20 & 15 & Concreto & $11^{\circ} 25^{\prime} 09.4^{\prime \prime} \mathrm{S} 58^{\circ} 47^{\prime} 19.9^{\prime \prime} \mathrm{W}$ \\
\hline
\end{tabular}

\section{Análise dos parâmetros físico-químicos}

As análises dos parâmetros físicos e químicos demonstraram que em sua maioria, estes, estão dentro dos limites estabelecidos pela Portaria MS no 05/2017, com exceção do parâmetro pH. As Tabelas 3 e 4 apresentam os resultados físico-químicos no período de alto índice pluviométrico e baixo índice pluviométrico, respectivamente.

Tabela 3: Resultados dos parâmetros físico-químicos no período de alto índice pluviométrico (Fevereiro, 2019).

\begin{tabular}{|c|c|c|c|c|c|c|c|c|c|c|c|}
\hline PARÂMETROS & P1 & $\mathrm{P} 2$ & P3 & P 4 & P5 & P6 & $\mathrm{P7}$ & P8 & P9 & $\mathrm{P} 10$ & VMP \\
\hline $\mathrm{pH}$ & 4,45 & 4,47 & 5 & 4,23 & 5,7 & 5,58 & 5,27 & 5,37 & 4,5 & 5,24 & 6 a 9,5 \\
\hline $\begin{array}{l}\text { Alcalinidade } \\
\text { (mg CaCO3.L-1) }\end{array}$ & 5,4 & 4 & 6 & 4 & 6,7 & 19,4 & 7,4 & 4 & 4,7 & 6,7 & - \\
\hline Cloretos (mg. L-1) & 60 & 30 & 70 & 40 & 70 & 30 & 70 & 50 & 80 & 90 & 250 mg. L-1 \\
\hline $\begin{array}{l}\text { Dureza } \\
\text { (mg CaCO3.L-1) }\end{array}$ & 15,4 & 5,87 & 8,8 & 6,6 & 18,33 & 17,6 & 6,6 & 0 & 6,6 & 8,07 & 500 mg. L-1 \\
\hline Cálcio (mg. L-1) & 5,9 & 1,47 & 2,05 & 0,9 & 2,05 & 7,05 & 2,06 & 2,64 & 3,82 & 2,9 & - \\
\hline $\begin{array}{l}\text { Magnésio } \\
(\mathrm{mg} . \mathrm{L}-1)\end{array}$ & 0,17 & 0,55 & 0,9 & 1,06 & 3,19 & 0 & 0,36 & 0 & 0 & 0,2 & - \\
\hline Condutividade elétrica $(\mu \mathrm{s} / \mathrm{cm})$ & 214,3 & 118,76 & 112,46 & 142,36 & 200,13 & 126 & 75 & 117,8 & 105,9 & 97,17 & - \\
\hline Ferro (mg. L-1) & $<0,25$ & $<0,25$ & $<0,25$ & $<0,25$ & $<0,25$ & $<0,25$ & $<0,25$ & $<0,25$ & $<0,25$ & $<0,25$ & 0,3 mg. L-1 \\
\hline
\end{tabular}

VMP = Valores Máximos Permitidos pela Portaria MS no 05/2017, ( - ) não descrito na legislação.

Tabela 4: Resultados dos parâmetros físico-químicos no período de baixo índice pluviométrico (Julho, 2019).

\begin{tabular}{|c|c|c|c|c|c|c|c|c|c|c|c|}
\hline PARÂMETROS & P1 & P2 & P3 & P 4 & P 5 & P 6 & P 7 & P 8 & P 9 & P10 & VMP \\
\hline $\mathrm{pH}$ & 4,56 & 4,45 & 5,11 & 4,44 & 5,21 & 5,61 & 5,27 & 5,41 & 4,6 & 5,41 & 6 a 9,5 \\
\hline Alcalinidade $\left(\mathrm{mg} \mathrm{CaCO}_{3} \cdot \mathrm{L}^{-1}\right)$ & 9,3 & 10 & 16 & 8,66 & 6,66 & 20 & 14 & 7,33 & 5,33 & 9,33 & - \\
\hline Cloretos (mg. $\left.\mathrm{L}^{-1}\right)$ & 30 & 20 & 30 & 30 & 30 & 20 & 30 & 20 & 20 & 20 & $250 \mathrm{mg} \cdot \mathrm{L}^{-1}$ \\
\hline Dureza $\quad\left(\mathrm{mg} \mathrm{CaCO}_{3} \cdot \mathrm{L}^{-1}\right)$ & 15,4 & 5,13 & 8,07 & 7,33 & 15,87 & 18,33 & 8,8 & 0 & 13,93 & 4,4 & $500 \mathrm{mg} . \mathrm{L}^{-1}$ \\
\hline Cálcio (mg. $\mathrm{L}^{-1}$ ) & 2,64 & 0,88 & 1,76 & 0,88 & 2,64 & 3,52 & 3,53 & 0 & 5,29 & 3,52 & - \\
\hline Magnésio (mg. $\mathrm{L}^{-1}$ ) & 2,13 & 0,7 & 0,85 & 1,23 & 2,46 & 2,3 & 0 & 0 & 0,16 & 0 & - \\
\hline Condutividade elétrica $(\mu \mathrm{s} / \mathrm{cm})$ & 217,8 & 123,4 & 132 & 160 & 244,4 & 140 & 94,9 & 129,4 & 126,4 & 105 & - \\
\hline Ferro (mg. $\left.\mathrm{L}^{-1}\right)$ & $<0,25$ & $<0,25$ & $<0,25$ & $<0,25$ & $<0,25$ & $<0,25$ & $<0,25$ & $<0,25$ & $<0,25$ & $<0,25$ & $0,3 \mathrm{mg} \cdot \mathrm{L}^{-1}$ \\
\hline
\end{tabular}

VMP = Valores Máximos Permitidos pela Portaria MS no 05/2017, ( - ) não descrito na legislação.

Com o intuito de demonstrar a influência da sazonalidade sobre a qualidade da água subterrânea, as

Tabelas 5 e 6 apresentam a análise de variância dos dados entre os períodos de chuva e de estiagem.

Observou-se ainda que algumas variáveis apresentaram uma relação de dependência com outras. Este padrão foi corroborado pelos resultados da correlação linear de Pearson entre os sete parâmetros físicoquímicos analisados, apresentados na Tabela 7. 
Tabela 5: Valores dos quadrados médios para os parâmetros físico-químicos da água de poços do bairro Módulo VI, sobre a análise de dois períodos amostrais (Chuvoso e estiagem).

\begin{tabular}{l|l|l|l|l|l|l|l|l}
\hline F. V. & G.L. & pH & Alcalinidade & Cloretos & Dureza & Cálcio & Magnésio & Condutividade Elétrica \\
\hline Épocas & 1 & $0,077^{\text {ns }}$ & $216,6^{*}$ & $17340^{*}$ & $3,952^{\text {ns }}$ & $5,735^{*}$ & $1,636^{*}$ & $10978,78^{*}$ \\
\hline Erro & 47 & 0,0304 & 3,539 & 112,55 & 3,012 & 1,143 & 0,31 & 300,48 \\
\hline C.V (\%) & 3,53 & 21,46 & 26,36 & 18,14 & 38,53 & 68,19 & 13,58 \\
\hline
\end{tabular}

*Significativo ao nível de $5 \%$ de probabilidade pelo teste F; ns Não significativo ao nível de $5 \%$ de probabilidade pelo teste F; GL: Grau de liberdade

Tabela 6: Valores médios dos parâmetros físico-químicos da água dos poços do bairro Módulo VI, Juína-MT, Brasil, 2019, entre os períodos chuvosos e de estiagem.

\begin{tabular}{l|l|l|l|l|l|l|l}
\hline Tratamentos & $\mathrm{pH}$ & Alcalinidade & Cloretos & Dureza & Cálcio & Magnésio & Condutividade Elétrica \\
\hline Seca & $4,91 \mathrm{~A}$ & $10,67 \mathrm{~A}$ & $25 \mathrm{~A}$ & $9,31 \mathrm{~A}$ & $2,46 \mathrm{~A}$ & $0,65 \mathrm{~A}$ & $120,37 \mathrm{~A}$ \\
\hline Chuva & $4,98 \mathrm{~A}$ & $6,87 \mathrm{~B}$ & $59 \mathrm{~B}$ & $9,83 \mathrm{~A}$ & $3,08 \mathrm{~B}$ & $0,98 \mathrm{~A}$ & $147,42 \mathrm{~B}$ \\
\hline
\end{tabular}

*Letras iguais na coluna não diferem entre si significativamente pelo teste Scott-Knott $(p<0,05)$.

Tabela 7: Matriz de correlação linear de Pearson para as variáveis físico-químicas da água dos poços do bairro Módulo VI, Juína-MT, Brasil, 2019.

\begin{tabular}{l|l|l|l|l|l|l|l}
\hline & $\mathrm{pH}$ & Alcalinidade & Cloretos & Dureza & Cálcio & Magnésio & Condutividade Elétrica \\
\hline $\mathrm{pH}$ & 1 & - & - & - & - & - & - \\
\hline Alcalinidade & $0,4549^{*}$ & 1 & - & - & - & - & - \\
\hline Cloretos & 0,1367 & $-0,4184^{\text {ns }}$ & 1 & - & - & - & - \\
\hline Dureza & 0,2391 & $0,3829^{*}$ & $-0,0265$ & 1 & - & - & - \\
\hline Cálcio & 0,1134 & $0,3052^{*}$ & 0,0677 & $0,5383^{*}$ & 1 & - & - \\
\hline Magnésio & 0,2065 & 0,1013 & $-0,0459$ & $0,5984^{*}$ & $-0,274^{\text {ns }}$ & 1 & - \\
\hline Condutividade Elétrica & $-0,1482$ & 0,0208 & $-0,1574$ & $0,6796^{*}$ & 0,0546 & $0,6612^{*}$ & 1 \\
\hline
\end{tabular}

*Significativo ao nível de $\mathrm{p}<0,05$ de probabilidade pelo teste de Pearson. ns indica valor não significativo pelo teste de Pearson em nível de $p<0,05$.

As concentrações e variações sazonais ocorridas em cada elemento, bem como a correlação existente entre eles, serão discutidas detalhadamente nos itens a seguir.

pH

Os valores do potencial hidrogeniônico, indicam as condições de acidez, neutralidade e basicidade da água em decorrência da presença dos íons hidrogênio H+ (SILVA et al., 2018). Nos poços analisados os resultados variaram de 4,23 a 5,58, com média de 4,98, durante o período de alto índice pluviométrico, e 4,44 a 5,61, com média de 4,91, no período de baixo índice pluviométrico, não tendo uma variação estatisticamente significativa (C.V. 3,53\%), conforme apresentado nas Tabela 5 e 6.0 pH correlacionou-se moderadamente com a alcalinidade ( $r=0,4549$, Tabela 7), indicando que este, é diretamente influenciado pela presença de substâncias alcalinas.

Os resultados do parâmetro $\mathrm{pH}$, corroboraram que as águas dos poços analisados têm valores abaixo do estabelecido pela Portaria MS no 05/2017, sendo consideradas ácidas e impróprias para o consumo humano. Este valor, pode estar relacionado com as características hidrogeomorfológicas naturais da região, bem como a precária proteção dos poços analisados.

Valores similares também foram encontrados por Silva et al. (2014), ao investigarem sobre a qualidade da água de poços de Cuiabá - MT. O pH médio encontrado foi de 5,0, indicando águas levemente ácidas. Segundo Santos (1997), o pH das águas subterrâneas varia geralmente entre 5,5 e 8,5.

A localização do poço em relação a fossa, pode contribuir ao aumento da acidez da água nas áreas 
investigadas, pois ao degradarem matéria orgânica, as bactérias decompositoras liberam $\mathrm{CO}_{2}$, o que pode acidificar o meio. Não obstante, o pH não apresenta efeito sobre a saúde da população consumidora, todavia, o intervalo estabelecido pelo Ministério da Saúde para água tratada $(6,0$ a 9,5), visa minimizar os efeitos corrosivos (para pH ácidos) ou incrustativo (para os elevados) nos encanamentos (LIBÂNIO, 2010).

\section{Alcalinidade}

A alcalinidade expressa a capacidade de tamponamento da água, em condições naturais seu aumento pode estar vinculado ao intemperismo das rochas formadoras da matriz do solo (QUEIROZ et al., 2016). Pode-se dizer que a alcalinidade é a concentração de hidróxidos, carbonatos e bicarbonatos e expressas em carbonato de cálcio (BRASIL, 2013). Em concentrações moderadas a alcalinidade não tem importância sanitária, porém em altas concentrações, pode conferir um sabor desagradável para a água.

As três formas de alcalinidade na água (bicarbonatos, carbonatos e hidróxidos), dependem do pH: $\mathrm{pH}>9,4$ indica a presença de hidróxidos e carbonatos; $\mathrm{pH}$ entre 8,3 e 9,4 indica a presença de carbonatos e bicarbonatos; $\mathrm{pH}$ entre 4,4 e 8,3 indica alcalinidade por apenas bicarbonatos. Em todos os poços aqui analisados, em ambos os períodos, foi possível constatar que o valor da alcalinidade refletiu a maior concentração de bicarbonatos, em decorrência deste parâmetro estar diretamente correlacionado com o $\mathrm{pH}$, que se manteve entre 4,4 e 8,3. A portaria do Ministério da Saúde, não estabelece valores mínimos ou máximos para este parâmetro, porém a maioria das águas naturais apresenta valores de alcalinidade variando de 30 a $500 \mathrm{mg}$. $\mathrm{L}^{-1}$ de $\mathrm{CaCO}_{3}$ (BRASIL, 2014).

Ao avaliar o parâmetro alcalinidade foi observada uma variação entre 4 (P2) e 19,7 mg de CaCO3 L-1 (P6), com média de 6,87 mg de $\mathrm{CaCO}^{-1} \mathrm{~L}^{-1}$ no período de alto índice pluviométrico e de 5,33 (P9) a $20 \mathrm{mg}$ de $\mathrm{CaCO}_{3} \mathrm{~L}-1$ no (P6) com média de $10,67 \mathrm{mg}$ de $\mathrm{CaCO}_{3} \mathrm{~L}^{-1}$ no período de baixo índice pluviométrico, indicando uma variação significativa entre os períodos analisados (C.V. 21,46\%) (Tabela 5 e 6).

A maior concentração de alcalinidade no período chuvoso pode ser decorrente do processo mais intenso de lixiviação, que carreia os bicarbonatos presentes no solo para o lençol freático. Libânio (2010) corrobora que valores mais elevados de alcalinidade, pode ser indicativo de lançamentos de efluentes doméstico não tratados, pelo intemperismo das rochas ou pela decomposição da matéria orgânica que propicia uma maior liberação de gás carbônico.

\section{Cloretos}

A quantidade de cloretos nas amostras analisadas variou significativamente conforme exposto nas Tabelas 5 e 6 (C.V. 26,36\%), variando de 30 e $90 \mathrm{mg}$. $\mathrm{L}^{-1}$, com média de $59 \mathrm{mg}$. $\mathrm{L}^{-1}$, no período de alto índice pluviométrico e de 20 a $30 \mathrm{mg}$. $\mathrm{L}^{-1}$, com média de $25 \mathrm{mg}^{-1}$, no período de baixo índice pluviométrico. Os valores estiveram sempre abaixo do estabelecido pelo ministério da saúde, que limitou a concentração de cloretos em até $250 \mathrm{mg}$. $\mathrm{L}^{-1}$ para água potável.

Embora estando abaixo do VMP, os poços amostrados variaram significativamente entre os períodos amostrados (Tabela 6), possuindo uma maior concentração de cloretos no período de alto índice 
pluviométrico, que provavelmente ocorreu devido a lixiviação dos minerais presente no solo, que chega no lençol freático causando um aumento significativo em suas concentrações.

Valores semelhantes aos aqui constatados, foram encontrados por Oliveira (2018) em Areia - PB, em que as concentrações de cloretos variaram de 30 e $50 \mathrm{mg}$. L'-1. Silva et al. (2018), também verificaram em sua pesquisa, altos valores de cloretos em poços na cidade do Macapá - AP, no período de alto índice pluviométrico, o que foi justificado pela interação da chuva ao longo do solo, que por sua vez, tinha predominância arenosa.

Os cloretos normalmente advêm da dissolução de minerais, no entanto, altas concentrações podem ser derivadas dos esgotos domésticos e industriais, podendo causar repulsa no paladar humano devido o sabor desagradável que esse íon confere, podendo ter propriedades laxativas (BRASIL, 2014).

\section{Dureza}

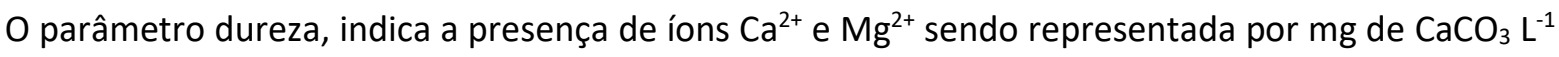
(BRASIL, 2014). Os resultados obtidos estão dentro do estabelecido pela Portaria MS no 05/2017, que é de, no máximo, $500 \mathrm{mg} \mathrm{CaCO}_{3} \mathrm{~L}^{-1}$. De acordo com os resultados da dureza observa-se que os valores estiveram entre 5,87 (P2) e 18,33 (P5) $\mathrm{mg} \mathrm{CaCO}_{3} \mathrm{~L}^{-1}$, com média de $9,83 \mathrm{mg} \mathrm{CaCO}_{3} \mathrm{~L}^{-1}$, no período chuvoso e 0 (P8) a 18, 33 (P6) $\mathrm{mg} \mathrm{CaCO}_{3} \mathrm{~L}^{-1}$, com média de $9,31 \mathrm{mg} \mathrm{CaCO}_{3} \mathrm{~L}^{-1}$, no período de estiagem, não diferindo significativamente entre os períodos analisados conforme a Tabela 5 e 6 (C.V. 18,14\%). A dureza correlacionou-se fracamente com a alcalinidade ( $r=0,3829$ Tabela 7).

Segundo Brasil (2014), a água pode ser classificada em mole ou branda: $<50 \mathrm{mg}$. $\mathrm{L}^{-1} \mathrm{de} \mathrm{CaCO}$; dureza

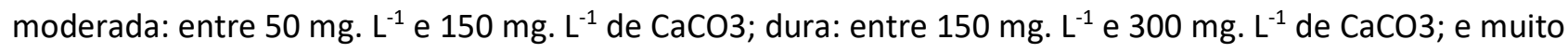
dura: $>300 \mathrm{mg}$. $\mathrm{L}^{-1}$ de CaCO3. Dessa forma, a água dos poços do bairro Módulo VI é caracterizada, em ambos os períodos, como água mole ou branda.

A dureza da água, pode ter causa natural devido a dissolução de rochas calcárias ricas em cálcio e magnésio, como pode ter influência antrópica, resultado do lançamento de efluentes domésticos e industriais (BRASIL, 2014). Ao analisar os resultados dos parâmetros cálcio e magnésio, observa-se que o cálcio esteve em maiores concentrações em relação ao magnésio em praticamente todos os poços, sendo o principal responsável pela dureza.

\section{Cálcio e Magnésio}

A presença de cálcio e magnésio nas águas subterrâneas, pode ser explicado devido a dissolução das rochas e por apresentarem comportamento químico similar, usualmente são discutidos em conjunto.

O cálcio variou de 0,9 (P4) a 7,05 (P6) mg. $\mathrm{L}^{-1}$, com média de 3,08 $\mathrm{mg}^{\mathrm{L}^{-1}}$, no período chuvoso e 0 (P8) a 5,29 (P9) mg. $\mathrm{L}^{-1}$, com média de $2,46 \mathrm{mg}$. $\mathrm{L}^{-1}$, no período de estiagem, apresentando C.V. de 38,53\% entre os dois períodos (Tabela 5). A maior concentração de cálcio no lençol freático no período chuvoso é explicada pela intensa lixiviação ocorrida pela ação da água no solo. O cálcio correlacionou-se fracamente com a alcalinidade $(r=0,3052)$ e moderadamente com a dureza $(r=0,5383)$, conforme a Tabela 7. 
Para o parâmetro magnésio, a variação foi de 0 (P6, P8, P9) a 3,19 (P5) mg. L $\mathrm{L}^{-1}$, com média de 0,98 $\mathrm{mg} . \mathrm{L}^{-1}$, no período de alto índice pluviométrico e 0 (P7, P8, P10) a 2,46 mg. $\mathrm{L}^{-1}$ (P5), com média de 0,65 mg. $\mathrm{L}^{-1}$, no período de baixo índice pluviométrico, correlacionando-se moderadamente com a dureza $(r=0,5984)$ (Tabela 7), com C.V. de 68,19\% (Tabela 5).

O teor de magnésio nas águas subterrâneas é consideravelmente menor que o de cálcio, pois os minerais que fornecem esse elemento são mais estáveis diante do intemperismo químico (STEIN et al., 2012).

Embora a Portaria MS no 05/2017 não estabeleça VMP para cálcio e magnésio, a literatura preconiza um valor máximo desejável de $75 \mathrm{mg}$. L $\mathrm{L}^{-1}$ e o máximo permissível de $200 \mathrm{mg}$. L $\mathrm{L}^{-1}$ (OMS, 1999), valores estes não ultrapassados nos poços amostrados. Resultados semelhantes a esta pesquisa foram encontrados por Stein et al. (2012), em que o teor de cálcio nas águas subterrâneas estudadas variou de 1,56 a 8,98 mg. L-1 e magnésio variou de 0,71 a 2,37 mg. $\mathrm{L}^{-1}$ com média de 1,46 mg. $\mathrm{L}^{-1}$.

Rapant et al. (2015), ao avaliarem o impacto da composição química da água subterrânea na saúde dos habitantes da República Eslovaca constataram que a mortalidade principalmente por doenças cardiovasculares e oncológicas, bem como doenças do sistema gastrointestinal e respiratório, é marcadamente mais baixas com concentrações de cálcio variando de 78 a $155 \mathrm{mg}^{\text {. L }}{ }^{-1}$ e magnésio de 28 a 54 mg. $\mathrm{L}^{-1}$.

\section{Condutividade elétrica}

A condutividade elétrica, representa a capacidade que a água tem de conduzir corrente elétrica, devido à presença de íons de sais, dessa forma quanto maior for a presença de íons dissolvidos, maior será a condutividade elétrica da água (ESTEVES, 1998).

De acordo com os resultados encontrados, pode-se notar uma variação significativa (C.V.=13,58\%), com valor mínimo de $75 \mu \mathrm{S} . \mathrm{cm}^{-1}$ (Poço 7) e um valor máximo de 214,26 $\mu \mathrm{S}$. cm-1 (Poço 1), com média de $147,42 \mu \mathrm{S} . \mathrm{cm}^{-1}$ no período chuvoso. No período de estiagem, o mínimo foi de $94,9 \mu \mathrm{S} . \mathrm{cm}^{-1}$ (Poço 7 ) e o máximo foi $244,4 \mu \mathrm{S}$. $\mathrm{cm}^{-1}$ (Poço 5), com média de $120,37 \mu \mathrm{S} . \mathrm{cm}^{-1}$. A condutividade elétrica correlacionouse moderadamente com a dureza $(r=0,6796)$ e com o magnésio $(r=0,6612)$, conforme a Tabela 7. A maior concentração no período chuvoso, pode ser indicativo da lixiviação dos sais presentes no solo para os poços amostrados, ou pela presença de material orgânico resultado da contaminação por esgoto doméstico advindo de fossas.

De acordo com Esteves (1998) a condutividade elétrica pode sofrer influência das condições geoquímicas e do clima da região. A Portaria MS no 05/2017 não estabelece VMP para esse parâmetro, porém Libânio (2010) afirma que as águas naturais usualmente apresentam condutividade elétrica inferior a $100 \mu \mathrm{S}$. $\mathrm{cm}^{-1}$, podendo chegar até $1000 \mu \mathrm{S} . \mathrm{cm}^{-1} \mathrm{em}$ corpos d'água que recebem grandes quantidades de cargas de eluentes domésticos e industriais.

\section{Ferro}

Todos os poços, em ambos os períodos não apresentaram variação estatisticamente significativa, 
com valores $<0,25 \mathrm{mg}$. L $\mathrm{L}^{-1}$ e dentro do limite estabelecido pela Portaria MS no 05/2017, que é de 0,3 mg. $\mathrm{L}^{-1}$. A presença de ferro, pode estar ligada à característica particular do solo, que é lixiviado para a água ou em decorrência de problemas construtivos dos poços.

Embora a presença do ferro não traga nenhum inconveniente tóxico à saúde da população, sua presença acima do VMP pode conferir um sabor desagradável a água, podendo causar depósitos nas canalizações e presença de ferrobactérias, causando sérios problemas no que tange a vida útil dos poços. $O$ ferro é de extrema importância para a saúde humana pois atua na formação da hemoglobina do sangue, em excesso pode causar problemas cardíacos e diabetes e em escassez, anemia (MENEZES, 1992; IRIS, 2004).

Freddo (2018) analisando a qualidade da água em Benevides - PA constatou concentrações de ferro variando de $0,00 \mathrm{mg}$. $\mathrm{L}^{-1}$ a 1,3 mg. $\mathrm{L}^{-1}$, com uma média de média de $0,2 \mathrm{mg}$. $\mathrm{L}^{-1}$ no período chuvoso e $0,00 \mathrm{mg}$. $\mathrm{L}^{-1}$ a $0,4 \mathrm{mg}$. $\mathrm{L}^{-1} \mathrm{com}$ média de $0,1 \mathrm{mg} \cdot \mathrm{L}^{-1}$ no período de estiagem.

\section{Análise dos Parâmetros Microbiológicos}

De acordo com os resultados dos parâmetros microbiológicos apresentados na Tabela 9, no período de estiagem todos os poços apresentaram contaminação por coliformes totais, no período chuvoso somente o poço 8 (10\%) não apresentou contaminação por coliformes totais. Quanto aos coliformes termotolerantes, estes também se mantiveram presentes em $100 \%$ dos poços analisados no período de estiagem, já no período chuvoso os poços P2, P3, P4, P6, P7, P9, 10 (70\%), apresentaram contaminação por coliformes termotolerantes, estando em desacordo com a legislação, que determina ausência em $100 \mathrm{~mL}$ de água.

Tabela 8: Resultados das análises da qualidade da água dos poços do bairro Módulo VI, para os parâmetros microbiológicos no período de alto índice pluviométrico e baixo índice pluviométrico (fevereiro e julho, 2019).

\begin{tabular}{l|l|l|l|l}
\hline Poço & \multicolumn{2}{|l|}{ Coliformes totais (em 100 ml) } & \multicolumn{2}{l}{ Coliformes termotolerantes Escherichia coli (em 100 ml) } \\
\hline & Estiagem & Chuva & Estiagem & Chuva \\
\hline P1 & + & + & + & - \\
\hline P2 & + & + & + & + \\
\hline P3 & + & + & + & + \\
\hline P4 & + & + & + & + \\
\hline P5 & + & + & + & - \\
\hline P6 & + & + & + & + \\
\hline P7 & + & + & + & + \\
\hline P8 & + & - & + & - \\
\hline P9 & + & + & + & + \\
\hline P10 & + & + & + & + \\
\hline \% & $100 \%$ positivo & $90 \%$ positivo & $100 \%$ positivo & $70 \%$ positivo \\
\hline
\end{tabular}

Legenda: ( + ) Positivo; ( - ) Negativo.

A presença de coliformes nos poços analisados pode estar vinculado à pequena profundidade dos poços e à pequena distância entre poço e fossa, situação essa corroborada por Silva e Araújo (2003), em Feira de Santana - BA, que ao analisarem 120 amostras de água verificaram que a presença de coliformes termotolerantes estava vinculada a poços rasos com até 10 metros de profundidade.

Nos poços P1, P5 e P8, não foram detectados coliformes termotolerantes no período chuvoso. Tal fato pode ser elucidado pela maior diluição do efluente das fossas, devido ao aumento do volume de água no nível freático, diminuindo assim a concentração desses microrganismos e, por conseguinte, a densidade 
da população bacteriológica. Vale ressaltar que o método utilizado, detecta concentrações acima de 80 Unidade formadoras de colônias (UFC), logo, não é possível afirmar que os referidos poços não apresentam contaminação, e sim que não houve detecção pelo método.

A contaminação da água, por esses patogênicos, é preocupante, pois podem causar graves problemas de saúde, como: desordens gastrointestinais, infecções em órgãos respiratórios, pele, ouvido olhos e trato urinário (LEVY et al., 2004). Eckhardt et al. (2009), ao analisarem a qualidade da água dos poços no bairro Bom Jesus, em Carlinda - MT, também registraram um percentual elevado de contaminação por coliformes totais (100\%) e para Escherichia coli (91\% - chuvoso; $79 \%$ - estiagem).

Com base nos resultados das análises microbiológicas, e considerando os requisitos mínimos obrigatórios da Resolução CONAMA no 396/2008, que obriga que até a Classe 3 deve haver ausência de coliformes termotolerantes em $100 \mathrm{~mL}$ de água, foi possível classificar o manancial como Classe 4. A Classe 4 abrange águas de aquíferos, conjunto de aquíferos ou porção desses, com alteração de sua qualidade por atividades antrópicas, e que somente possam ser utilizadas, sem tratamento, para o uso preponderante menos restritivo.

O artigo 14 da Resolução CONAMA no 396/2008 esclarece que independentemente dos valores máximos permitidos para as Classes 3 e 4, qualquer aumento de concentração de contaminantes deverá ser monitorado, sua origem identificada e medidas adequadas de prevenção e controle deverão ser adotadas pelos órgãos competentes (BRASIL, 2008).

\section{CONCLUSÕES}

As águas dos poços amostrados e utilizados pela população não atendem aos padrões de potabilidade para os parâmetros $\mathrm{pH}$, coliformes totais e coliformes termotolerantes, estabelecidos pela Portaria $n^{\circ}$ 05/2017 do Ministério da Saúde. Considerando os requisitos mínimos obrigatórios da Resolução CONAMA no 396/2008, que obriga que até a Classe 3 deve haver ausência de coliformes termotolerantes em $100 \mathrm{~mL}$ de água, foi possível classificar as águas do aquífero, como Classe 4.

As águas possuíam baixos valores de $\mathrm{pH}$, sendo ácidas e impróprias para o consumo. A elevada contaminação por coliformes totais e termotolerantes, ocorreu na grande maioria dos poços analisados e em ambos os períodos, o que reflete diretamente as condições higiênico-sanitárias dos poços, e expõe a saúde dos consumidores à uma série de riscos.

A pequena distância entre os poços e as fossas e a pequena profundidade dos poços são fatores frequentemente observados no bairro amostrado, que favoreceram a contaminação do lençol freático. Outro fator importante a ser mencionado é a vedação dos poços, que preponderantemente se mostrou ineficiente, tornando-os passíveis à contaminação externa.

Observou-se ainda uma variação significativa nos parâmetros alcalinidade, cloretos, cálcio, magnésio e condutividade elétrica entre o período chuvoso e de estiagem, o que denota a influência da sazonalidade na qualidade hídrica subterrânea. As variações entre os períodos são decorrentes principalmente da maior lixiviação ocorrida no período chuvoso, que carreia os elementos do solo para o lençol freático. 
Conclui-se que a população do bairro Módulo VI está consumindo água fora dos padrões de potabilidade estabelecidos pela legislação brasileira, podendo refletir diretamente na saúde da população consumidora. Os resultados expostos nesse trabalho evidenciam a necessidade da implantação de medidas mitigadoras de forma efetiva, bem como a necessidade de monitoramento contínuo da qualidade da água do bairro.

\section{REFERÊNCIAS}

ANA. Agência Nacional das Águas. Cuidando das Águas: Soluções para melhorar a qualidade dos recursos hídricos. Programa das nações unidas para o Meio Ambiente. 2 ed. Brasília ANA, 2013.

APHA. American Public Health Association. Standard Methods for the Examination of Water and Wastewater. 19 ed. New York: APHA, 1995.

ARAÚJO, R. V.. Planejamento urbano da cidade de JuínaMT, com foco no plano diretor da cidade: Obstáculos, avanços, limites e possibilidades. Dissertação (Mestrado em Ambiente e Desenvolvimento) - Centro Universitário UNIVATES. Lajeado, 2014.

AYACH, L. R.. As condições socioeconômicas, o saneamento básico e a qualidade da água subterrânea em Anastácio (MS): aspectos relacionados à percepção ambiental. Tese (Doutorado em Geografia) - Universidade Estadual Paulista, Rio Claro, 2011.

AYACH, L. R.. Implicações socioeconômicas e sanitárias na qualidade das águas freáticas da cidade de Anastácio-MS. Dissertação (Mestrado em Geografia) - Universidade Federal de Mato Grosso do Sul, Dourados, 2002.

BASTOS, M. L.. Caracterização da qualidade da água subterrânea: estudo de caso no município de Cruz das Almas - Bahia. Monografia (Bacharelado) - Universidade Federal do Recôncavo da Bahia, Cruz das Almas, 2013.

BRAGAGNOLO, L.; FERRAZZO, S. T.; BRUM, F. M.; KORF, E. P.; MOSSI, A, J.. Qualidade do lixiviado e sua interferência na água subterrânea adjacente ao aterro sanitário de Palmeira das Missões (RS). REGA - Revista de Gestão de Água da América Latina, v.15, n.8, 2018. DOI: http://doi.org/10.21168/rega.v15e8

FREDDO, V. J. F.. Qualidade das águas subterrâneas rasas do aquífero Barreiras: Estudo de casos em Benevides - $P A$. Dissertação (Mestrado em Recursos Hídricos) - Universidade Federal do Pará, Belém, 2018.

BORTOLI, J.. Qualidade Físico-Química e Microbiológica da água utilizada para o consumo humano e dessedentação animal em propriedades rurais produtoras de leite na região do Vale do Taquari/RS. Dissertação (Mestrado em Ambiente e Desenvolvimento) - Centro Universitário UNIVATES, Lajeado, 2016.

BRASIL. Fundação Nacional de Saúde. Manual de saneamento. 3 ed. Brasília: FUNASA, 2007.

BRASIL. Ministério da Saúde. Fundação Nacional de Saúde. Manual de controle da qualidade da água para técnicos que trabalham em ETAs. Brasília: FUNASA, 2014.

BRASIL. Ministério da Saúde. Portaria n. 05 de 28 de setembro de 2017. Brasília: MS, 2011.

BROOKS, D.; CECH, I.. Nitrates and bacterial distribution in rural domestic water supplies. Water Research, v.13, p.3341, 1979

CAPP, N.; AYACH, L. R.; SANTOS, T. M. B.; GUIMARÃES, S. R. T.. Qualidade da água e fatores de contaminação de poços rasos na área urbana de Anastácio (MS). Geografia Ensino \& Pesquisa, v.16, n.3, 2012. DOI: https://doi.org/10.5902/223649947581

CONAMA. Conselho Nacional do Meio Ambiente. Resolução n. 396, de 03 de abril de 2008. Brasília: CONAMA, 2008.

ECKHARDT, R. R.; LIMA, A. S.; SILVA, W. P.. Mapeamento e avaliação da potabilidade subterrânea do município de Lajeado, RS, Brasil. Ambi-Água, v.4, n.1, p.58-80, 2009. DOI: http://doi.org/10.4136/1980-993X

ESTEVES, F. A.. Fundamentos de limnologia. 2 ed. Rio de Janeiro: Interciência Ltda., 1998.

FERREIRA, D. F.. SISVAR: Um programa para análise e ensino de estatística. Revista Symposium, v.6, n.2, p.36-41, 2008.

FRANÇA, J. A. O.. A pluriatividade na sustentabilidade socioambiental do Parque Laranjeira em Juína/MT. Dissertação (Mestrado em Ambiente e Desenvolvimento) Centro Universitário UNIVATES, Lajeado, 2016.

FUNASA. Fundação Nacional de Saúde. Manual de Saneamento. 4 ed. Brasília: FUNASA, 2006.

IBGE. Instituto Brasileiro de Geografia e Estatística. Cidades Mato Grosso. IBGE, 2010.

IRIS. Integrated Risk Information System. List of IRIS Substances. IRIS, 2004.

LIBÂNIO, M.. Fundamentos de Qualidade e Tratamento de Água. 3 ed. Campinas: Átomo, 2010.

LEVY, C. E.. Manual de microbiologia clínica para o controle de infecções em Serviços de Saúde. Agência nacional de vigilância sanitária, 2004.

MENEZES, M. A. S.. Ferro-bactérias em água subterrânea: estudo de caso no estado do Ceará. Dissertação (Mestrado) Universidade de São Paulo, São Paulo, 1992.

MERTEN, G. H.; MINELLA, J. P.. Qualidade da água em bacias 
hidrográficas rurais: Um desafio atual para a sobrevivência futura. Agroecologia e Desenvolvimento Rural Sustentável, v.3, n.4, 2002.

OLIVEIRA, V. S.. Qualidade de água de poços tubulares utilizada no cultivo de hortaliças. Monografia (Bacharelado) - Universidade Federal da Paraíba, Areia, 2018.

OMS. Organization Mundial de la Salud. Guias para la calidad del água potable. 2 ed. Genebra: OMS, 1999.

RAPOSA, M. V.; GOMES, J. B.. Qualidade da água de poços de abastecimento do bairro São José Operário do município de Juína - MT. In: CONGRESSO BRASILEIRO DE GESTÃO AMBIENTAL, 8. Anais. Campo Grande, 2017.

RAPANT, S. K. F.; CVEČKOVÁ, V.; ĎURŽA, A.; STEHLÍKOVÁ, B.; SEDLÁKOVÁ, D.; ŽENIŠOVÁ, Z.. Chemical composition of groundwater and relative mortality for cardiovascular diseases in the Slovak Republic. Environmental Geochemic Health, v.37, p.745-756, 2015. DOI: http://doi.org/10.1007/s10653-015-9700-5

SANTOS, A. C.. Noções de Hidroquímica. In: Hidrologia: Conceitos e aplicações. Fortaleza: UFPE, 1997.

SILVA, A. B.; BRITO, J. M.; DUARTE, J. D. S.; BRAZ, A. S.; SILVA, R. A.; FILHO, E. D. S.. Análise físico-química da água utilizada para consumo nas escolas municipais da zona urbana de Esperança/PB. Biota Amazônia, v.8, n.3, p.49-52, 2018. DOI: http://dx.doi.org/10.18561/2179-

5746/biotaamazonia.v8n3p49-52

SILVA, D. D.; MIGLIORINI, R. B.; SILVA, E. D. C. E. S.; LIMA, Z. M. D.; MOURA, I. B.. Falta de saneamento básico e as águas subterrâneas em aquífero freático: região do Bairro Pedra Noventa, Cuiabá (MT). Engenharia Sanitária Ambiental, v.19 n.1, p.43-52, 2014. DOI: https://doi.org/10.1590/S1413$\underline{41522014000100005}$

SILVA, L. P.; BARBOSA, J. P.; SILVA, G. A.. Análise exploratória de dados da qualidade da água de poços amazonas na cidade de Macapá, Amapá, Brasil. Águas Subterrâneas, v.32, n.1, p.43-51, 2018. DOI: http://dx.doi.org/10.14295/ras.v32i1.28941

SILVA, R. C. A.; ARAUJO, T. M.. Qualidade da água do manancial subterrâneo em áreas urbanas de Feira de Santana (BA). Revista Ciência \& Saúde Coletiva, v.8, n.4, p.1019-1028, 2003. DOI: https://doi.org/10.1590/S1413$\underline{81232003000400023}$

SILVA, R. R.; BOCCHI, N.; FILHO, R. C. R.; MACHADO, P. F. L.. Introdução à Química Experimental. 2 ed. São Carlos: EduFSCar, 2014.

SILVA, T. V.. Uso da terra e qualidade da água no Assentamento Antonio Conselheiro, Mato Grosso. Dissertação (Mestrado em Ambientes e Sistemas de Produção Agrícola) - Universidade do Estado de Mato Grosso, Tangará da Serra, 2016.

SOUZA, C. S.. Estudo da qualidade da água e das condições de abastecimento para consumo humano na comunidade de Gravatá de baixo - Muritiba - Bahia. Monografia (Bacharelado em Engenharia Sanitária e Ambiental) Universidade Federal do Recôncavo da Bahia, Cruz das Almas, 2015.

STEIN, P.; FILHO, J. B. D.; LUCENA, L. R. F. D.; CABRAL, N. M. T.. Qualidade das águas do aquífero Barreiras no setor sul de Natal e norte de Parnamirim, Rio Grande do Norte, Brasil. Revista Brasileira de Geociências, v.42, p.226-237, 2012. DOI: http://dx.doi.org/10.5327/Z0375-75362012000500018

WHO; UNICEF. World Health Organization. United Nations Children's Fund. Progress on drinking water, sanitation and hygiene: 2017 update and SDG baselines. Geneva: WHO, 2017.

ZAN, R. A.; COSTA, A. L.; COSTA, J. B.; MENEGUETTI, D. U. D. O.. Análise microbiológica de amostras de água de poços rasos localizados no município de Buritis, região do Vale do Jamari, Rondônia, Amazônia Ocidental. Revista Eletrônica em Gestão, Educação e Tecnologia Ambiental, v.8, n.8, p.1867-1875, 2012. DOI: http://dx.doi.org/10.5902/223611707293

A CBPC - Companhia Brasileira de Produção Científica (CNPJ: 11.221.422/0001-03) detém os direitos materiais desta publicação. Os direitos referem-se à publicação do trabalho em qualquer parte do mundo, incluindo os direitos às renovações, expansões e disseminações da contribuição, bem como outros direitos subsidiários. Todos os trabalhos publicados eletronicamente poderão posteriormente ser publicados em coletâneas impressas sob coordenação da Sustenere Publishing, da Companhia Brasileira de Produção Científica e seus parceiros autorizados. Os (as) autores (as) preservam os direitos autorais, mas não têm permissão para a publicação da contribuição em outro meio, impresso ou digital, em português ou em tradução. 